\title{
COVID-19 Vaccination and Bariatric Surgery
}

\author{
Rujittika Mungmungpuntipantip $^{1}$ (D) Viroj Wiwanitkit ${ }^{2}$
}

Received: 29 September 2021 / Revised: 7 October 2021 / Accepted: 4 December 2021 / Published online: 22 January 2022

(c) The Author(s), under exclusive licence to Springer Science+Business Media, LLC, part of Springer Nature 2021

\section{Dear Editor,}

We would like to share ideas on "COVID-19 Vaccination and Timing of Bariatric Surgery: Considerations and Concerns for Patients with Severe Obesity [1]." Pazouki et al. noted that "we encourage operating on fully vaccinated patients...... the second shot of the vaccine and the surgery, with more preference for the latter due to its lower likelihood of infection after surgery" [1]. We agree that it is necessary to prevent COVID-19 for the patient. However, we should have a careful consideration for vaccination management. An obese case usually has a high blood viscosity [2], and the COVID-19 vaccine can induce increased blood viscosity [3]. Additionally, after any operation, a change of blood viscosity can occur [4]. Hence, there might be a possible problem of hyperviscosity in an obese subject after vaccination. Based on these factors, the COVID-19 vaccination should be provided before operation. Pre-operation COVID19 can also help decrease possible COVID-19 infection of the hospitalized patient during pre-operation period. In case that an emergency surgery is required, there must be a good monitoring of complication of post-operation COVID-19 vaccination.

\section{Declarations}

Ethics Approval This article does not contain any studies with human participants or animals performed by any of the authors.

Consent to Participate Informed consent does not apply.

Conflict of Interest The authors declare no competing interests.

\section{References}

1. Pazouki A, Shahabi S,c Sheikhbahaei E,Mokhber S, Jazi AHD, Kermansaravi1 M. COVID-19 vaccination and timing of bariatric surgery: considerations and concerns for patients with severe obesity. Obes Surg. 2021: 1-3. https://doi.org/10.1007/ s11695-021-05734-x.

2. Guiraudou M, Varlet-Marie E, Raynaud de Mauverger E, Brun JF. Obesity-related increase in whole blood viscosity includes different profiles according to fat localization. Clin Hemorheol Microcirc. 2013;55(1):63-73.

3. Joob B, Wiwanitkit V. Expected viscosity after COVID-19 vaccination, hyperviscosity and previous COVID-19. Clin Appl Thromb Hemost. 2021;27:10760296211020832.

4. Müller R, Musikić P. Hemorheology in surgery-a review. Angiology. 1987;38(8):581-92.

Publisher's Note Springer Nature remains neutral with regard to jurisdictional claims in published maps and institutional affiliations.
Rujittika Mungmungpuntipantip

Bangkok, Thailand

2 Dr. D. Y. Patil University, Pune, India 